\title{
Implications of technological learning on the prospects for renewable energy technologies in Europe
}

\author{
Martine A. Uyterlinde ${ }^{\mathrm{a}, *}$, Martin Junginger ${ }^{\mathrm{b}}$, Hage J. de Vries ${ }^{\mathrm{a}}$, \\ André P.C. Faaij ${ }^{\mathrm{b}}$, Wim C. Turkenburg ${ }^{\mathrm{b}}$ \\ ${ }^{a}$ Policy Studies Department, Energy Research Centre of the Netherlands (ECN), P.O. Box 1, 1755 ZG Petten, The Netherlands \\ ${ }^{\mathrm{b}}$ Copernicus Institute for Sustainable Development and Innovation, Utrecht University, Heidelberglaan 2, 3584 CS Utrecht, The Netherlands
}

Received 26 January 2007; accepted 6 February 2007

Available online 2 April 2007

\begin{abstract}
The objective of this article is to examine the consequences of technological developments on the market diffusion of different renewable electricity technologies in the EU-25 until 2020, using a market simulation model (ADMIRE REBUS). It is assumed that from 2012 a harmonized trading system will be implemented, and a target of $24 \%$ renewable electricity (RES-E) in 2020 is set and met. By comparing optimistic and pessimistic endogenous technological learning scenarios, it is found that diffusion of onshore wind energy is relatively robust, regardless of technological development, but diffusion rates of offshore wind energy and biomass gasification greatly depend on their technological development. Competition between these two options and (existing) biomass combustion options largely determines the overall costs of electricity from renewables and the choice of technologies for the individual member countries. In the optimistic scenario, in 2020 the market price for RES-E is $1 € \mathrm{ct} / \mathrm{kWh}$ lower than in the pessimistic scenario (about $7 \mathrm{vs}$. $8 € \mathrm{ct} / \mathrm{kWh}$ ). As a result, total RES-E production costs are 19\% lower, and total governmental expenditures for RES-market stimulation are $30 \%$ lower in the optimistic scenario.
\end{abstract}

(C) 2007 Elsevier Ltd. All rights reserved.

Keywords: Technological learning; Renewable electricity; Market simulation

\section{Introduction}

In the last decades, technical development of renewable energy technologies has progressed in terms of market introduction, reduction of investment costs and reliability. Renewable energy technologies are regarded as an option to reduce both greenhouse gas emissions and (Europe's) dependency on imported oil and gas. In some countries, renewable technology manufacturing industries have experienced large growth, leading to an increase in employment in the sectors involved. In line with these developments, ambition levels of policies and targets increased over time. An important milestone in this respect

\footnotetext{
*Corresponding author. Tel.: + 31224 564369; fax: + 31224568338 .

E-mail addresses: uyterlinde@ecn.nl (M.A. Uyterlinde), m.junginger@chem.uu.nl (M. Junginger), a.faaij@chem.uu.nl (A.P.C. Faaij), w.c.turkenburg@chem.uu.nl (W.C. Turkenburg).
}

in Europe was the adoption of the Renewables Directive (European Parliament, 2001) setting a target of achieving $22 \%$ electricity production from renewable energy sources (RES-E) in the year 2010, compared to $14.5 \%$ in 1999. Jansen and Uyterlinde (2004) gave an overview of the process that has led to the adoption of this Directive and an assessment of its implementation.

As most grid-connected RES-E technologies need financial support to penetrate the market, the design and ambition level of support policies determines to a great extent the successful diffusion of different RES-E technologies. Presently, there is a large variety of support schemes across Europe. Roughly, two main types of support schemes have emerged, apart from investment support, which is given by nearly all EU countries. Feed-in tariffs, which offer a fixed, technology-specific revenue for each $\mathrm{kWh}$ RES-E production, are generally favoured by investors because they provide security for a number of 
years in advance. The other major type of support scheme is based on a quota obligation, usually imposed on suppliers of electricity. Apart from producing RES-E, obliged actors can meet a possible shortage of their quota by purchasing Tradable Renewable Energy Certificates (TRECs). This system, based on a market for RES-E production, introduces competition between different technologies and is thereby expected to function in a cost-efficient way. However, in the short run when a liquid market is yet to develop, many investors regard it as a more uncertain support scheme. ${ }^{1}$

For most RES-E technologies, such as onshore wind energy, biomass combustion and photovoltaics, technological development has resulted in both declining investment costs and electricity production costs over the last few decades (Goldemberg and Johansson, 2004). For example, the cost of electricity produced by onshore wind turbines have roughly been reduced by a factor five over the last 20 years, due to technological development (BTM, 2000). Also for coming decades, production costs are expected to decline further, especially for advanced technologies, which only recently have been commercialized (e.g. offshore wind energy), or are still in the research, development and demonstration phase (e.g. biomass integrated gasification combined cycle (BIG/CC) for electricity production).

A wide variety of energy models have been developed to provide policy makers with a better insight into the complexities of energy systems under various policy objectives. Many of these describe the complete energy system either with a technical 'bottom-up' (systems engineering) focus or with a macro-economic 'top-down' approach. Examples of bottom-up models are MESSAGE, MARKAL and ERIS (see Seebregts et al., 1999 for an overview). Top-down models are for example CETA, DICE or DEMETER (Peck and Teisberg, 1992; Nordhaus, 1993; van der Zwaan et al., 2002). Most of the energy models that cover complete energy systems have analysed the impact of varying technological development, and find that it may have a strong impact on total energy system costs and the shares of individual technologies in the overall energy system composition. Gerlagh and van der Zwaan (2004) report that already small variations in the assumptions on the rate of technological progress can lead to strongly deviating results in energy models.

Next to general energy models, energy sector models exist that concentrate particularly on prospects for one fuel or market. ADMIRE REBUS is one of these sector models, developed with the purpose of modelling the fragmented and changing market for RES-E in Europe (Daniëls and Uyterlinde, 2005). Other models that pay specific attention to the role of RES-E are SAFIRE (Whiteley et al., 2003) and GREEN-X (Huber, 2004). These sector-specific models for the RES-E market so far

\footnotetext{
${ }^{1}$ de Vries et al. (2003) and Reiche et al. (2003) provide overviews of the current state of the art in the EU-15 and the NMS respectively.
}

have not reported on variations in technology diffusion trends under different technology learning scenarios.

Against the background of a changing market for RES$\mathrm{E}$ in Europe induced by the Renewables Directive of the EU, and the potential impact of varying development of RES-E technologies, objectives of this article are to examine:

- which consequences differing technological developments may have on the diffusion of specific RES-E technologies in the EU-25 until 2020;

- which technologies seem most attractive for individual countries, and what resulting production costs and total governmental expenditures are (in the frame of a chosen policy scenario);

- which market diffusion trends are relatively robust and which ones are most sensitive to learning effects.

The main aim of this article is to explore effects of varying technological developments on the market diffusion of different renewable electricity technologies in the EU-25 until 2020. This exercise is not an attempt to forecast the diffusion of RES-E in the EU-25, as this also strongly depends on policy developments, price development of fossil fuels and other exogenous factors. Furthermore, as the analysis focuses on the supply side, it does not explicitly address learning effects for demand-side technologies, although these will also benefit from experience, leading to higher efficiencies and reduced electricity demand growth, as highlighted by Laitner and Stanstad (2004).

Section 2 starts with describing the methodology applied, explaining first the ADMIRE REBUS simulation model and next the concept of experience curves (ECs). Section 3 provides an overview of input data and assumptions made for the analysis, while Section 4 presents results and a discussion of the outcomes. In addition, in Section 5 several methodological issues are discussed. Finally, in Section 6 conclusions are drawn.

\section{Methodology}

\subsection{The ADMIRE REBUS model}

A simulation approach was chosen for ADMIRE REBUS because it allows technologies to be taken into account that have a niche in the market but are not yet cost-effective. The simulation approach deals with investment decisions under different support schemes from the point of view of the investor. It therefore allows for a representation of barriers involved in the development of electricity markets for renewables, such as investment risks, lead times, failure rates in permission procedures and transaction costs. Offering a vintage approach ${ }^{2}$ for new

\footnotetext{
${ }^{2}$ The model keeps track of renewable capacity by year of installation, e.g. by vintage.
} 
and existing capacity, ADMIRE REBUS is a dynamic simulation tool. The model is capable of providing insight not only into the functioning of a mature market for renewable energy, but also into the transition to such a market, because it can deal with unstable planning horizons and high risk investments. Results of the ADMIRE REBUS model include equilibrium prices, trade flows, technology implementation, government expenditures and much more in the national and European markets under different scenarios.

\subsubsection{Model data base}

The model data base contains detailed information on costs and potentials of 12 RES-E technologies in the EU-25 Member States. A brief overview of all technologies is given in Table 1. A detailed background report on all potentials and costs is also available (de Noord et al., 2004; de Vries, 2004), as well as a specification of renewables support policies in individual MS (see Uyterlinde et al., 2003).

For all renewable technologies within a country, 'realistic' future potentials have been assessed. These potentials establish the maximum amount of production that can be realised based on a specific technology and in a specific country at a certain point in time, and include both technical and non-technological constraints. The realistic potentials have been constructed in a systematic way, relating each potential to its main constraining factor (see Table 1). It is assumed that biomass is not traded between MS member countries, and no biomass is imported from outside the EU-25.

Developments in both the primarily constraining factor and the technology-dependent translation factors lead to changes of maximum potentials over time. Within the simulation process, various dynamic limitations on the deployment growth are taken into account, related to

Table 1

Overview of technological input data in ADMIRE REBUS. More detailed data is given by de Noord et al. (2004) and de Vries (2004)

\begin{tabular}{|c|c|c|c|c|c|}
\hline & $\begin{array}{l}\text { Main constraining factor (technology } \\
\text { bands) }\end{array}$ & $\begin{array}{l}\text { Load factor } \\
(\%)\end{array}$ & $\begin{array}{l}\text { Inv. Costs } \\
\left(€ / \mathrm{kW}_{\mathrm{e}}\right)\end{array}$ & $\begin{array}{l}\text { Annual O\&M } \\
\text { (\% of Inv.) }\end{array}$ & $\begin{array}{l}\text { Life-time } \\
\text { (years) }\end{array}$ \\
\hline Wind onshore & Wind speed $(<5$ to $>9 \mathrm{~m} / \mathrm{s})$ & $10-28$ & $860-1240$ & $2-4$ & 20 \\
\hline Wind offshore & Wind speed $(<7$ to $>9 \mathrm{~m} / \mathrm{s}) \&$ water depth & $18-36$ & $1690-2080$ & $3-4$ & 20 \\
\hline Biomass cofiring $^{\mathrm{a}}$ & $\begin{array}{l}\text { Suitable biomass types: (1), (2) and } \\
\text { available co-firing potential }\end{array}$ & 80 & $190-220$ & 6 & 15 \\
\hline Biomass combustion & Suitable biomass types: (1), (2) & $70-90$ & $1590-6000$ & $4-5$ & 15 \\
\hline Biomass $\mathrm{CHP}^{\mathrm{b}}$ & Suitable biomass types: (1) & $74-90$ & 2500 & 4 & 15 \\
\hline Biomass gasification $^{c}$ & Suitable biomass types: (1), (2), (3) & 63 & 3400 & $5-6.5$ & 15 \\
\hline Biomass digestion & Suitable biomass types: (3), (4) & $75-80$ & 5000 & 6 & 15 \\
\hline Solar PV ${ }^{\mathrm{d}}$ energy & $\begin{array}{l}\text { Solar radiation } \\
\left(<1000 \text { to }>1800 \mathrm{kWh} / \mathrm{m}^{2} / \text { year }\right)\end{array}$ & $9-18$ & 5400 & 1 & 25 \\
\hline Geothermal & Available current and future sites & 65 & $1700-2500$ & 2 & 20 \\
\hline Tidal & Available current and future sites & 26 & 1750 & 0.8 & 30 \\
\hline $\begin{array}{l}\text { Large hydro } \\
(>10 \mathrm{MW})\end{array}$ & Available current and future sites & $16-70$ & $1660-8270$ & $0.7-1.3$ & 30 \\
\hline \multirow[t]{2}{*}{ Small \& medium hydro } & Available current and future sites & $28-57$ & $1410-6050$ & $3.1-6.3$ & 25 \\
\hline & Biomass types & & $\begin{array}{l}\text { Cost range }(€ / \\
\mathrm{PJ})^{\mathrm{d}}\end{array}$ & $\begin{array}{l}\text { Total potential } \\
\text { in EU-25 }(\mathrm{PJ})^{\mathrm{e}}\end{array}$ & \\
\hline (1) & $\begin{array}{l}\text { Energy crops, forest residues, agricultural } \\
\text { residues (barley, maize, oil crop, rapeseed, } \\
\text { wheat) }\end{array}$ & & $1.8-6.4$ & $\begin{array}{l}2070 \text { (energy } \\
\text { crops) } \\
1080 \text { (forest } \\
\text { residues) } \\
1280 \text { (agricult. } \\
\text { residues) }\end{array}$ & \\
\hline (2) & Solid manure & & 0 & 125 & \\
\hline (3) & Biodegradable part of MSW & & 0 & 213 & \\
\hline \multirow[t]{2}{*}{ (4) } & $\begin{array}{l}\text { Liquid manure, landfill gas and sewage } \\
\text { sludge }\end{array}$ & & 0 & 112 & \\
\hline & & & & $+6.54\left(\mathrm{TWh}_{\mathrm{e}}\right)^{\mathrm{f}}$ & \\
\hline
\end{tabular}

The reference year for all data is 2001 .

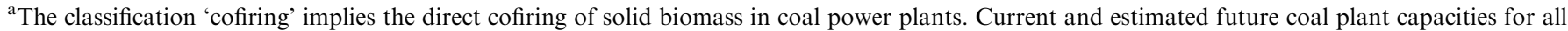

MS are included in the model. The model assumes a maximum cofiring share, increasing from $10 \%$ in 2010 to $20 \%$ in 2020 .

${ }^{\mathrm{b}}$ Combined heat and power.

${ }^{\mathrm{c}}$ In this article, the classification 'biomass gasification' implies the use of biomass integrated gasification/combined cycle (BIG/CC) plants.

${ }^{\mathrm{d}}$ Photovoltaic.

${ }^{\mathrm{e}}$ These potentials are based on literature studies, and can be considered conservative estimates.

${ }^{\mathrm{f}}$ The potential for energy from liquid manure and sewage is calculated from a yield in $\mathrm{kWh} / \mathrm{ton}$. 
e.g. the success rate of planning procedures and the speed of opening up (biomass) resources.

An endogenous cost calculation module determines operational costs of renewable technologies, expressed in terms of the required green price (RGP), i.e. the initial investment deficit faced by an investor in renewable generation capacity. ${ }^{3}$ This means that the RGP incorporates the investment and production costs minus the revenues the producer expects to obtain apart from support policies.

Data on technological cost components is documented by de Noord et al. (2004) while assumptions on future cost developments are discussed in Section 3.2. Finally, the RGP calculation includes a required return on equity of $12 \%$ with a variable, country- and technology-dependent risk adder that takes into account the effect of risks and uncertainties on various cost and revenue components.

The data base on support policies is based on a detailed inventory of different instruments for operational and investment support applied in the EU-25 Member States. It takes into account the levels of support, and terms and conditions such as the number of years for which support is granted.

\subsubsection{The general simulation approach}

Fig. 1 gives an overview of the overall functionality of the model, with the relevant factors. The basic building blocks of the model are supply curves, based on renewable potentials of individual technological options, and demand curves, consisting of demand segments, which are based on policies.

The supply curve consists of technology options, characterized by their potentials (in GWh) and their costs (in $€ \mathrm{ct} / \mathrm{kWh}$ ). From year to year, the model constructs a new supply curve based on installed capacities and shares of realisable potential that can become available for each technology and country. In parallel, a stepwise demand curve is constructed. For this purpose, the model translates each Member State's RES-E support policy into a separate demand segment with a demand size (in GWh) and a bid price (in $€ c t / \mathrm{kWh}$ ). ${ }^{4}$ This translation is directly related to the type of policy. Finally, the model applies a matching algorithm in which all demand segments are matched with eligible supply options. The model accounts both for the discriminative characteristics of policies and for the ability of producers to choose whether they produce for the domestic market or wish to trade their production.

The simulation is done on a year-to-year basis, up to $2020 .^{5}$ Although the modelled actors make investment

\footnotetext{
${ }^{3} \mathrm{An}$ annual average green price to be received from the RES-E market in order to achieve a zero net present value.

${ }^{4}$ The demand curve includes segments for all past policies, which support production that is still operational, such as feed-in tariffs that are guaranteed for a specific number of years.

${ }^{5}$ The model is capable to perform simulations until 2040.
}

decisions based on their expectations, there is no overall foresight mechanism, and therefore the model results may demonstrate lock-in effects for individual technologies, or path dependency. This feature is useful when analysing different technology learning scenarios.

\subsubsection{Cost calculations}

In this section, cost calculations are explained for a single-quota system, as this will be the main policy regime used in the remainder of the article. ${ }^{6}$ The supply and demand curves of an individual country or a trading region are exemplified in Fig. 2. The figure consists of two parts. On the left-hand side, the 'green market' is displayed, i.e. the amount of RES-E produced that receives additional support. The cost supply curve consists of technology options, characterized by their potentials (in GWh) and their costs (in $€ \mathrm{ct} / \mathrm{kWh}$ ). For intermittent electricity sources (e.g. wind and PV), an additional cost factor may be included. The demand curve is set by a penalty level and a quota obligation, for which all production except large hydro is eligible. Unless the market is short of TRECs, an equilibrium price will be established below the penalty level. On the right-hand side of the graph represents the production that can compete on the grey market, but still counts for achieving the target, such as existing large hydro. The additional production costs (striped area) represent costs of options additional to the electricity commodity price, assuming no separate investment support is given. This cost measure represents a lower bound to the actual costs incurred, because it does not include any profit margins for either producers or traders. The model also calculates total government and end-user expenditures (grey area), representing the amount of money spent in order to stimulate renewables deployment. ${ }^{7}$ For a trading scheme these expenditures are calculated based on the assumption that the equilibrium price is assumed to be the price paid for all supply in the green market. ${ }^{8}$ The difference between total expenditures and additional production costs is the producers' surplus. Each year, a new quota is set, and a new supply curve is calculated, resulting in a new equilibrium price. Also, the electricity commodity price level may change over time.

\footnotetext{
${ }^{6}$ ADMIRE REBUS is also capable of dealing with other (more complex) policy support systems, e.g. a mixture of feed-in tariffs and quota systems in different countries. For a more detailed description, see Daniëls and Uyterlinde (2005)

${ }^{7}$ Note that the total expenditures are only the expenditures on top of the electricity commodity price. No further distinction is made in this paper who is covering these expenditures (e.g. electricity utilities, national governments or the end consumer).

${ }^{8}$ The assumption that the market clearing equilibrium price will be set at the cost level of the marginal option holds for a perfect, transparent market, see for instance Morthorst (2000). In practice, however, price setting may be less straightforward, involving long-term contracts. As is clear from Fig. 2, a disadvantage of the quota-based system is that there may be a group of producers that gain large profits, because their operational costs are relatively low, see also Verbruggen (2004).
} 


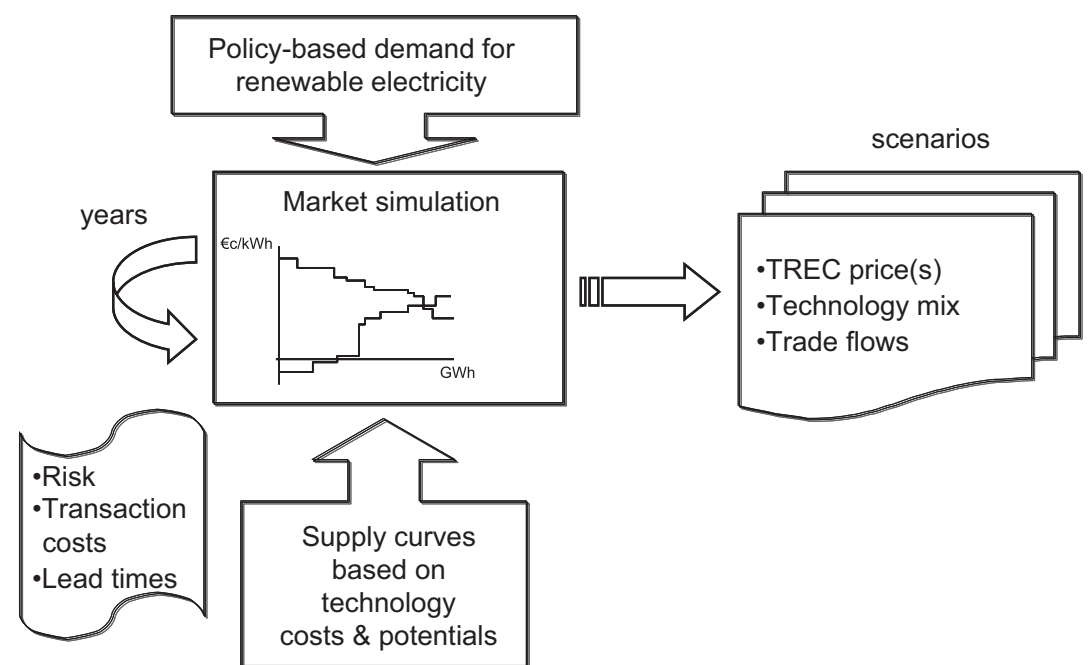

Fig. 1. Schematic overview of the ADMIRE REBUS model.

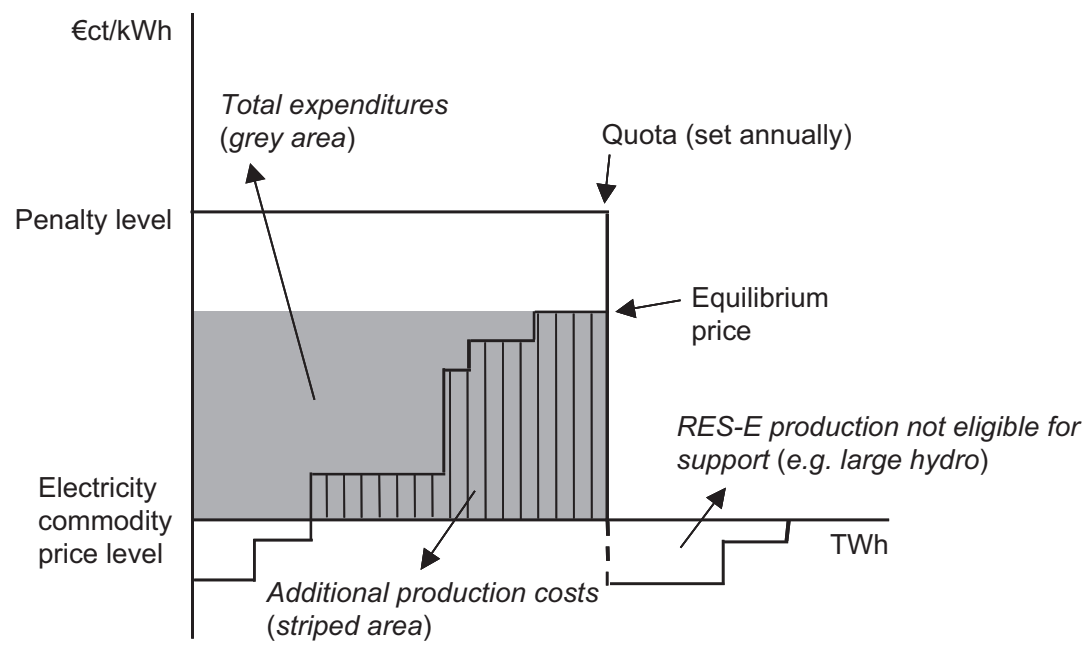

Fig. 2. Example of cost calculations, performed annually in the model. The baseline is equal to the electricity commodity price, which may change over time. The quota is set annually (depending on the chosen target).

\subsection{Technological learning and ECs}

When making scenarios or models for future development and penetration of new (energy) technologies, one has to take into account the technological development and associated cost reductions. Typically, this can be modelled in two ways. Either cost reductions are exogenous, i.e. they are determined in advance as a constant cost reduction over time (based on bottom-up cost estimates), independent of the actual diffusion rate of the technology. The second possibility is to model change endogenously, assuming that costs of a technology depend to a large extent on the actual diffusion rate of the technology. This is based on the assumption, that with increasing use of the technology, mechanisms such as learning-by-doing, learning-by-using, upscaling and mass production yields experience, which leads to lower production costs. This relationship was quantified by the Boston Consultancy Group (BCG), which in 1968 formulated the EC concept (BCG, 1968). An EC (as defined by the $\mathrm{BCG}$ ) describes the change in production costs (a total of labour, capital, R\&D, marketing, overhead etc.) as a fixed percentage with every cumulative doubling of production. The basic EC can be expressed as

$C_{\mathrm{Cum}}=C_{0} \mathrm{Cum}^{\mathrm{b}}$,

$\log C_{\mathrm{Cum}}=\log C_{0}+b \log$ Cum,

$\mathrm{PR}=2^{\mathrm{b}}$,

where $C_{\text {Cum }}$, cost per unit; $C_{0}$, cost of the first unit produced; Cum, cumulative (unit) production; $b$, experience index; PR, progress ratio.

The definition of the 'unit' may vary: in many cases a unit is a product (for example a car or an airplane). In relation to energy technologies, often the unit is the capacity of an energy technology (e.g. the capacity of a gas turbine). The progress ratio (PR) is a parameter that expresses the rate at which costs (per unit of capacity) 
decline each time the cumulative capacity doubles. For example, a PR of $0.8(80 \%)$ equals a $20 \%$ cost decrease for each doubling of the cumulative capacity.

While there is no natural law that production costs have to decline in this fashion, empirically this trend has been observed historically many times (see for an overview of various studies Argote and Epple (1990). Also for many (renewable) energy technologies, ECs have been devised, such as photovoltaic modules, wind turbines, gas turbines and fuel cells. An overview is presented by McDonald and Schrattenholzer (2001).

Since the mid-1990s, the EC concept has been applied in several energy and climate models, both in top-down models such as DEMETER (van der Zwaan and Seebregts, 2004) and bottom-up models such as MESSAGE, MARKAL, ERIS (Seebregts et al., 1999) and IMAGE/TIMER (Hoogwijk, 2004). In bottom-up models, investment costs of specific renewable energy technologies are modelled using ECs. This allows to demonstrate and quantify benefits of investing early in emerging technologies that are not competitive at the moment of their deployment (Seebregts et al., 1999). Therefore, this approach was also included in the ADMIRE REBUS model.

\section{Policy and technology assumptions and input data}

\subsection{Policy scenario's to 2020}

For the current paper, one reference policy scenario was designed to serve as a common background to the different technology development scenarios. Main characteristics of this policy scenario are the EU-25 wide introduction of a quota system, including trade of TRECs from 2012 onwards, and a fixed target for the EU-25 for 2020 of $24 \%$ RES-E production. This scenario is meant to provide a plausible background to the analysis of technology learning effects, rather than giving a forecast of how support policies in Europe might develop. Therefore, it is based on a generic policy instead of technology-specific support. If different technologies would benefit from specific subsidies, differentiated by country, as is the present situation, it would be difficult to assess the effect of the assumptions regarding technology learning.

In detail, the reference scenario is characterized as follows. Until 2008, all EU Member States are expected to continue their current national support policies. Reflecting the uncertainty in policy developments, we assume that from 2008 until 2012 all MS replace these with generic support. This implies that they still use their preferred type of instrument, but they harmonize the support level to $5 € \mathrm{ct} / \mathrm{kWh},{ }^{9}$ not differentiated by technology. This level has been chosen to reflect a moderate ambition level, and is comparable to the current buy-out price (penalty level) of the Renewables Obligation in the UK. Many countries in Western Europe that use feed-in

\footnotetext{
${ }^{9}$ Producers receive this on top of the electricity commodity price.
}

tariffs currently pay slightly higher levels (de Vries et al., 2003). At the time of writing, it does not seem likely that national governments opt for a joint approach towards achieving their renewables targets in $2010 .{ }^{10}$ Therefore, the scenario does not expect international trade in RES-E to take off until 2012. After 2012, it is assumed that the quota system is used, in which TRECs are traded in a harmonized European market in which international trade in TRECs takes place. Capacity installed before 2012 has still the right to make use of domestic schemes. ${ }^{11}$

All MS are assumed to regard the 2010 targets conform the Renewables Directive as leading in the sense that the target provides the upper bound to what can be installed each year. Several studies have shown, that the $22 \%$ target for 2010 is very ambitious, and are unlikely to be met. In 2002 , the RES-E production in the EU-15 was only $14.8 \%$ (EREF, 2004), a marginal increase compared to $14.5 \%$ in 1997. Roughly three quarters of this production is covered by large-scale hydropower, a source with almost no geographical potential to increase further. With the continuation of present policies in the MS, it is likely that only $17-19 \%$ RES-E will be achieved by 2010 (European Commission, 2004; Uyterlinde et al., 2003). Targets for 2020 are yet to be negotiated, presumably in 2007 . Therefore, the assumption was made that countries slow down their ambition level compared to the target of $22 \%$ in 2010, and settle for a moderately ambitious increase, yielding an overall share of $24 \%$ RES-E in $2020 .{ }^{12}$ Table 2 presents the targets used in the reference policy scenario.

Due to the chosen method of constructing MS targets by extrapolation, the implicit assumption is made that countries that were ambitious in their 2010 targets remain so, while less ambitious countries are not required to 'compensate' beyond 2010. Obviously, more advanced methods of determining a distribution of targets over countries are possible, see for instance Voogt et al. (2001) for a discussion on burden sharing options based on different equity principles, but these are beyond the scope of this paper. It should be noted, however, that the impact of this assumption is limited, because in a harmonized, open TREC market in Europe beyond 2012, the 24\% overall target is leading for the amount of additional renewable capacity installed.

The general background to this scenario is provided by the baseline projection until 2030 done for the European Commission (Mantzos et al., 2003), which is the source for

\footnotetext{
${ }^{10}$ For instance, the diversity of implementations of the guarantees of origin (GO) requirement in the Renewables Directive by different MS is not expected to facilitate a harmonized market in GO or other certificates in the short term (Linden et al. 2004).

${ }^{11}$ In those cases where currently available policy data indicates a longer operational period, e.g. feed-in tariffs that are guaranteed for 10 years.

${ }^{12}$ The targets for individual MS have been constructed by extrapolating their average growth rates conform their commitment for 1997-2010 in the Renewables Directive, while assuming that the resulting target for 2016 is actually agreed for 2020 . This implies also, that in this scenario the original targets of $22 \%$ in 2010 are not (likely to be) met.
} 
Table 2

RES-E targets for 2010 and $2020^{\mathrm{a}}$

\begin{tabular}{|c|c|c|c|c|c|}
\hline & $\begin{array}{l}\text { Actual production } 1997 \text { (1999 for } \\
\text { NMS) }(\%)^{\text {b }}\end{array}$ & $\begin{array}{l}\text { Target } 2010 \\
(\%)^{\mathrm{b}}\end{array}$ & $\begin{array}{l}\text { Target } 2020 \\
(\%)^{\mathrm{b}}\end{array}$ & $\begin{array}{l}\text { Projected total electricity consumption } \\
2020 \text { (TWh) }\end{array}$ & $\begin{array}{l}\text { RES-E target } 2020 \\
\text { (TWh) }\end{array}$ \\
\hline Austria & 72.7 & 78.1 & 80.6 & 82.1 & 66.2 \\
\hline Belgium & 1.1 & 6 & 8.3 & 107.6 & 8.9 \\
\hline Cyprus & 0.05 & 6 & 9.2 & 5.7 & 0.5 \\
\hline Czech Republic & 3.8 & 8 & 10.3 & 88.8 & 9.1 \\
\hline Denmark & 8.7 & 29 & 38.4 & 45.7 & 17.6 \\
\hline Estonia & 0.2 & 5.1 & 7.8 & 9.8 & 0.8 \\
\hline Finland & 24.7 & 31.5 & 34.6 & 99.4 & 34.4 \\
\hline France & 15 & 21 & 23.8 & 654.1 & 155.7 \\
\hline Germany & 4.5 & 12.5 & 16.2 & 656.7 & 106.4 \\
\hline Greece & 8.6 & 20.1 & 25.4 & 88.0 & 22.3 \\
\hline Hungary & 0.7 & 3.6 & 5.2 & 64.4 & 3.4 \\
\hline Ireland & 3.6 & 13.2 & 17.6 & 39.7 & 7.0 \\
\hline Italy & 16 & 25 & 29.2 & 393.0 & 114.7 \\
\hline Latvia & 42.4 & 49.3 & 53.1 & 12.2 & 6.5 \\
\hline Lithuania & 3.3 & 7 & 9 & 16.8 & 1.5 \\
\hline Luxemburg & 2.1 & 5.7 & 7.4 & 9.1 & 0.7 \\
\hline Malta & 0 & 5 & 7.7 & 4.2 & 0.3 \\
\hline Netherlands & 3.5 & 9 & 11.5 & 161.9 & 18.6 \\
\hline Poland & 1.6 & 7.5 & 10.7 & 255.6 & 27.3 \\
\hline Portugal & 38.5 & 39 & 39.2 & 72.6 & 28.5 \\
\hline Slovak & 17.9 & 24.6 & 28.3 & 47.0 & 13.3 \\
\hline \multicolumn{6}{|l|}{ Republic $^{c}$} \\
\hline Slovenia & 29.9 & 33.6 & 35.6 & 15.8 & 5.6 \\
\hline Spain & 19.9 & 29.4 & 33.8 & 365.4 & 123.5 \\
\hline Sweden & 49.1 & 60 & 65 & 175.3 & 113.9 \\
\hline United & 1.7 & 10 & 13.8 & 538.1 & 74.3 \\
\hline \multicolumn{6}{|l|}{ Kingdom } \\
\hline EU-25 & 14.5 & 22 & 24 & $4,008.9$ & 961.0 \\
\hline
\end{tabular}

Sources: Renewables Directive (European Commission, 2001) and EU Outlook until 2030 (Mantzos et al., 2003).

${ }^{a}$ The targets for 2020 have been constructed by extrapolation. Targets already formulated by individual MS for 2020 were not taken into account, because only a few countries have set such targets, and for reasons of consistency in ambition levels.

${ }^{\mathrm{b}}$ As percentage of total electricity consumption.

${ }^{\mathrm{c}}$ The target for Slovakia in 2010 has been adjusted to the fact that the Slovakian government intends to renegotiate the target, which was originally set at $31 \%$ (Anonymous, 2004).

the electricity demand trends for individual EU MS. Electricity commodity prices (based on industrial prices minus transport cost, see Uyterlinde et al., 2003) are expected to increase from a current EU-wide average of 3 to $5 € \mathrm{ct} / \mathrm{kWh}$ in 2020 due to an expected reduction in generating overcapacity and a carbon premium.

\subsection{Assumptions on technology development}

This article investigates possible impacts of technological learning and associated cost reductions of RES-E technologies on the penetration, total cost and distribution over the various MS. Technological learning can be modelled endogenously by using ECs, as currently done in many energy models. However, given the empirical nature of ECs, the PR of a technology is always to a certain extent uncertain. Most studies rather present ranges in which the PR may vary, and recommend using these ranges in scenario-analysis ${ }^{13}$ (Neij et al., 2003; Schaeffer et al., 2004;

\footnotetext{
${ }^{13}$ These ranges may appear small at first glance (e.g. $77-80 \%$ for photovoltaics). However, with an increasing number of cumulative
}

Junginger et al., 2004a, b). Therefore, an optimistic and a pessimistic technology learning scenario (OTLS and PTLS) were formulated. In the OTLS, the lower (i.e. more optimistic) boundaries of these ranges have been utilized. The main underlying assumption in the OTLS is, that technological development of RES-E options is actively pursued and supported by policy measures. As recently suggested by Schaeffer et al. (2004), 'investing in learning, ${ }^{14}$ may lead to lower (i.e. better) PRs (at least in the case of photovoltaic modules). Such a scenario would for example include financing of long-term R\&D research, financial

\section{(footnote continued)}

doublings of capacity, even such a small difference may cause huge differences in the outcome of the scenarios, as the PR is one of the most sensitive parameters in energy models (van der Zwaan and Seebregts, 2004).

${ }^{14}$ The total amount of support spent on technology development up to the point of market break-even. This happens not only through RTD actions but also through support of learning-by-using and learning-byinteracting processes (Schaeffer et al., 2004). However, it must be emphasised that this is a very complex matter, and it is no easy undertaking of quantifying and predicting the effect of such policy measures beforehand. 
support for pilot plants, building and supporting user networks etc. In contrast, in the PTLS, effects of slower technology development are explored. This would correspond to fewer efforts from both the public and the private sector to further develop RES-E technologies.

In these scenarios, the investment cost reduction ${ }^{15}$ of four technologies have been modelled using the EC approach: solar electricity (PV), onshore wind, offshore wind and biomass gasification. These renewable energy technologies both have a significant geographical potential within the EU-25 and substantial cost reduction opportunities (Faaij et al., 1998; IEA/OECD, 2003; de Noord et al., 2004; Schaeffer et al., 2004; Junginger et al., 2004a, b). The remaining technologies were either deemed to have no significant cost reduction potential (such as different forms of biomass combustion or large-scale and small-scale hydro) or to have too high costs and limited potential until 2020 (e.g. geothermal and wave energy) to have any significant impact on the European electricity market (IEA/OECD, 2003; de Noord et al., 2004).

Technological learning of RES-E technologies occurs often on a global level, i.e. improvements of a technology (e.g. a wind turbine) are rapidly adopted all over the world. This seems justified, as most producers of renewable energy technologies (such as wind turbines, PV modules or biomass boilers) sell their products worldwide. As the EC concept uses cumulative installed capacity as a proxy for accumulated experience, worldwide (and not only European) development of capacities should be used to measure cumulative experience. However, the ADMIREREBUS model currently only models the development in the EU-25 MS. To take technological developments and capacity additions achieved in the rest of the world (ROW) into account, also assumptions had to be made on the installed capacity development of each technology until 2020 in the ROW. These assumptions were deliberately chosen to be identical in both the OTLS and PTLS, allowing for a better comparison and interpretation of differing scenario results. In general, capacity growth expectations in the ROW were mainly based the world energy outlook (WEO)(IEA/OECD, 2002) ${ }^{16}$ and the reference scenario of the World energy, technology and climate policy outlook (WETO) (European Commission, 2003). ${ }^{17}$

\footnotetext{
${ }^{15}$ Other performance indicators, e.g. development of availabilities or conversion efficiencies were modelled exogenously (see de Noord et al., 2004).

${ }^{16}$ The WEO 2002 includes the IEAs projections of the global energy system until 2030, based on the IEAs World energy model. In their reference scenario, the overall share of non-hydro renewables is expected to grow $3.3 \%$ annually on a global level, but most growth is expected to occur in OECD countries, especially in those with strong measures to promote renewable energy.

${ }^{17}$ The WETO reference scenario provides a description of the future world energy system, under a continuation of the on-going trends and structural changes in the world economy, and is based on the POLES model. The share of RES-E is expected to increase from $2 \%$ in 2000 to $4 \%$ in 2030 .
}

Below, assumptions for the PRs and capacity growth outside the EU-25 are presented for each of the four technologies scrutinized (see Table 3 for an overview):

For photovoltaics, PRs of $77 \%$ and $80 \%$ were chosen for the OTLS and PTLS respectively, based on recent findings of Schaeffer et al. (2004). The capacity growth in the ROW was mainly based on WEO and WETO expectations (15 and $30 \mathrm{GW}$, respectively, in 2020). For the OTLS and PTLS scenarios, a further growth to $22 \mathrm{GW}$ in 2020 of installed PV capacity was assumed.

Regarding onshore wind, PRs of $81 \%$ and $85 \%$ are based on the approach that wind energy technology learns on a global level (Junginger et al., 2004a). For the ROW capacity growth until 2020, next to the WEO and WETO results, also forecasts based on expectations for market development (Molly and Ender, 2004; Westwood, 2004) were taken into account. Again, a moderate exponential growth was assumed, in between the WETO and the WEO scenario. This leads to $93 \mathrm{GW}$ installed onshore wind capacity in the ROW in 2020.

For offshore wind, the EC approach is not directly applicable, as not sufficient existing offshore wind farms exist so far. A possible method to overcome this issue is to analyze the cost reduction potential for each of the main components of offshore wind farms. These are wind turbines, foundations, electrical infrastructure and installation costs. For each of these components, it is possible to analyze the cost reduction potential. For example, cost reductions achieved for onshore turbines also benefit the cost of offshore turbines. Foundations like monopiles, gravity-based structures and tripod structures have been utilized for several decades in the offshore oil and gas industry. For each of these components, cost reduction trends and underlying mechanisms were analysed, and (where possible) separate ECs were set up. More detailed information is given by Junginger et al. (2004b). Regarding the development of offshore wind energy in the ROW, few forecasts or scenarios were found in the literature. An installed capacity of $680 \mathrm{MW}$ in 2008 was assumed based on expectations for North America (Westwood, 2004). In absence of any further estimates, from 2008 onward a moderate $10 \%$ annual increase of this capacity was used, resulting in $2.1 \mathrm{GW}$ offshore wind capacity in 2020 for the ROW.

Similarly to offshore wind farms, ECs for large-scale biomass gasification plants cannot be devised directly. However, as with offshore wind farms, estimates can be made for each component of gasification plants using the EC concept. Based on Faaij et al. (1998), assumptions were made for the cost reduction potential of specific plant components. These included standard components such as the fuel storage and preparation, and the entire steam cycle (including steam turbine and condenser) for which practically no cost reduction potential was assumed. Also standard costs for civil works, engineering piping, site preparation etc. were kept constant. For components specific to biomass gasification, such as the fuel feeding 
Table 3

Overview of assumptions on technological development in the two scenarios

\begin{tabular}{|c|c|c|c|c|}
\hline & $\begin{array}{l}\text { PR } \\
\text { OTLS } \\
(\%)\end{array}$ & $\begin{array}{l}\text { PR } \\
\text { PTLS } \\
(\%)\end{array}$ & $\begin{array}{l}\text { Assumed initial investment } \\
\text { costs in } 2001(€ / \mathrm{kW})\end{array}$ & Assumed capacity ROW 2001/2020 (GW) \\
\hline PV & 77 & 80 & 5400 & $1.5 / 22$ \\
\hline Wind onshore & 81 & 85 & $860-1240^{\mathrm{a}}$ & $6.1 / 93$ \\
\hline Wind offshore & $\mathrm{b}$ & $\mathrm{b}$ & $1690-2080$ & $0 / 2.1$ \\
\hline $\begin{array}{l}\text { Turbine } \\
\text { Foundation }\end{array}$ & $\mathrm{d}^{\mathrm{c}}$ & ${ }_{d}^{85^{c}}$ & & \\
\hline Conv. stations & $71^{\mathrm{c}}$ & $71^{\mathrm{c}}$ & & \\
\hline Cables & $62^{\mathrm{c}}$ & $62^{\mathrm{c}}$ & & \\
\hline Installation & 77 & 77 & & \\
\hline $\mathrm{BIG} / \mathrm{CC}$ & $91^{\mathrm{e}}$ & $93^{\mathrm{e}}$ & 3400 (in 2001) & See methodological discussion (Section 5) \\
\hline Pretreatment & 87 & 87 & OTLS: 1600 (in 2014) & \\
\hline Gasif. system and gas cleaning & 80 & 82 & PTLS: 2035 (in 2014) ${ }^{\mathrm{h}}$ & \\
\hline Comb. Cycle and compressor & $89^{f}$ & $90^{\mathrm{f}}$ & & \\
\hline Other components & 100 & 100 & & \\
\hline \multicolumn{5}{|c|}{$\begin{array}{l}{ }^{\text {a }} \text { Depending on the technology band (for a definition and detailed description of all technology bands, see de Noord et al., 2004). } \\
\text { b No aggregate PR is given, as the costs depend on an aggregate of several underlying ECs for the different components of an offshore wind farm, and } \\
\text { developments of e.g. onshore wind capacity. For further details see Junginger et al. (2004b). } \\
{ }^{\mathrm{c}} \text { With these components, also the speed of diffusion of onshore wind turbine and HVDC technologies influences the cost reduction (Junginger et al., } \\
2004 \mathrm{~b} \text { ). } \\
{ }^{\mathrm{d}} \text { Based on trend analysis, annual cost reduction of steel (the main component of monopile and tripod foundations) of } 2 \% \text { and } 1 \% \text { were assumed in the } \\
\text { OTLS and PTLS, respectively. } \\
\text { e This is an aggregated PR, based on the development of several underlying PRs for the different components listed below. For further details see Faaij } \\
\text { et al. (1998). } \\
{ }^{\mathrm{f}} \text { These values correspond well to the value given by Claeson Colpier and Cornland (2002) for natural gas turbine combined cycles (90\%). } \\
\text { g Based on } 10 \text { pilot plants until } 2014 \text {. } \\
{ }^{\mathrm{h}} \text { Based on three pilot plants until } 2014 \text {. }\end{array}$} \\
\hline
\end{tabular}

system, gasifier, tar cracker, cyclones, gas cooling and gas cleaning, estimates were made how upscaling a $30 \mathrm{MW}$ plant to $100 \mathrm{MW}$ and learning by building several plants may contribute to cost reductions for these components. Combining the estimates for all components, an overall PR varying between $91 \%$ and $93 \%$ was determined. Recent empirical research for plants utilizing fluidized bed boilers has shown that the new components show lower (i.e. better) PRs than overall plant investment costs (Koornneef, 2004). The PR of fluidized bed combustion power plants (which are somewhat similar in size and technology to gasification plants) was found to lie between $89 \%$ and $93 \%$, which is similar to our assumptions. Regarding the market introduction for biomass gasification, no suitable estimates or forecasts were found in literature. For that reason, assumptions were made based on the literature and expert opinions. It is assumed that several pilot plants (with increasing scale) are required to successfully develop commercial BIG-CC power plants. In the OTLS it was therefore assumed that until 2014, 10 demonstration BIG/CC plants are built. With these plants substantial experience can be gained, both to lower investment costs and to demonstrate technical reliability and commercial viability. $\mathrm{BIG} / \mathrm{CC}$ plants are then introduced in the market from 2014 onwards. In the PTLS, only three such pilot plants were assumed to be built. In combination with different PRs for gasification technology, the investment costs (and thus the CoE) differ significantly in the OTLS and PTLS scenario.

\section{Results and discussion}

\subsection{Technology-specific developments}

An overview of the development of RES-E electricity production from 2001 until 2020 is shown in Fig. 3. In Fig. 4, the development of electricity production volumes of the major biomass options and offshore wind energy are also displayed over time.

The net installed $P V$ capacity varies slightly from $1.2 \mathrm{GW}$ in the PTLS to $1.5 \mathrm{GW}$ in the OTLS, which lies in between WEO $(4 \mathrm{GW})$ and WETO $(1 \mathrm{GW})$ expectations for Europe. Until the year of harmonization (2012) PV is supported by national incentives, and installed capacity grows in both scenarios. After international trade starts in 2012, in the PTLS, no further capacity is added. In the OTLS, capacity continues to grow slightly, ${ }^{18}$ but the total electricity contribution (less than $3 \mathrm{TWh}$ ) to the overall RES-E target for 2020 is marginal (below $0.3 \%$ ).

\footnotetext{
${ }^{18}$ The growth only occurs in Italy. This has two reasons. First, investment costs are reduced over $60 \%$ until 2020 (see Table 4). Total production cost are $7.5 € \mathrm{ct} / \mathrm{kWh}$ in 2020 . Second, Italy has a relatively high electricity commodity price $(6.2 € \mathrm{ct} / \mathrm{kWh})$ compared to other countries. Therefore, PV can compete with other RES-E options in Italy, but not in other countries, at least not until 2020.
} 


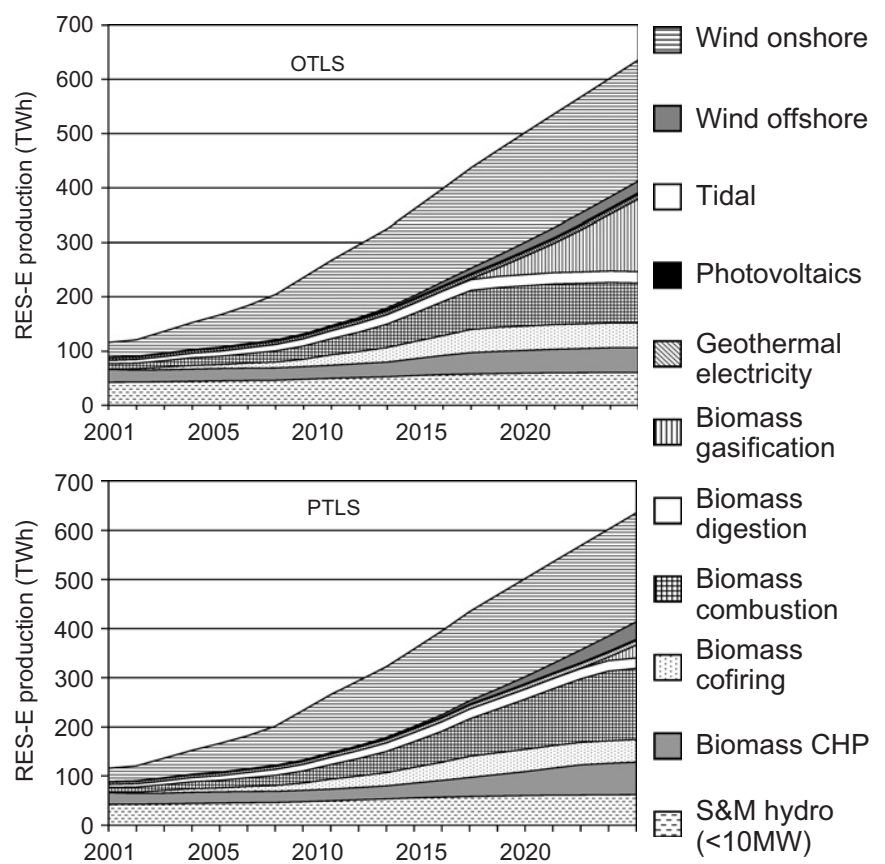

Fig. 3. RES-production of all technologies in the OTLS and PTLS. Large scale hydro has been excluded, as the annual production is almost constant (2001: 312 TWh, 2020: $326 \mathrm{TWh}$ in both scenarios). The contributions of tidal and PV electricity are marginal and barely visible.

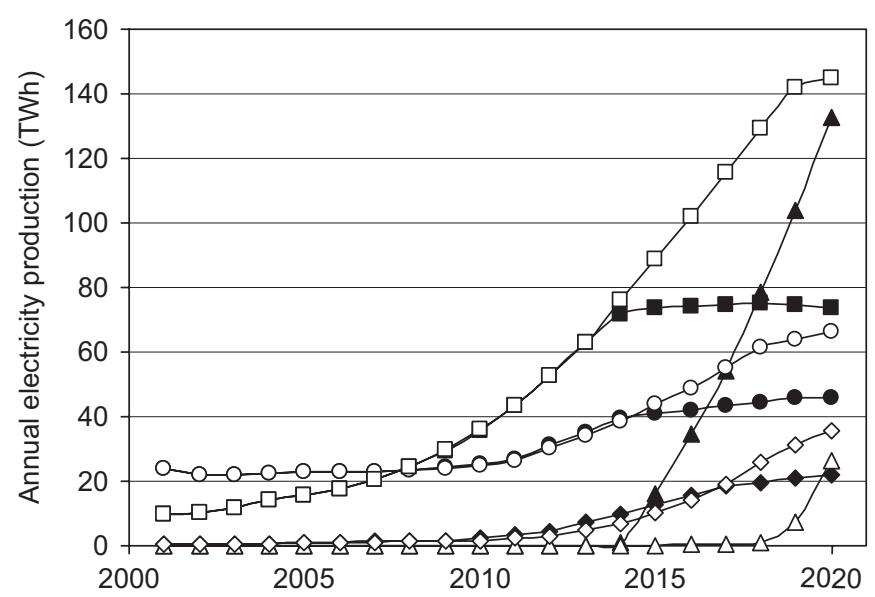

$$
\begin{array}{ll|}
\rightarrow-\text { Biomass CHP OTLS } & - \text { Biomass combustion OTLS } \\
\neg-\text { Biomass gasification OTLS } & - \text { Wind offshore OTLS } \\
\multimap-\text { Biomass CHP PTLS } & -\square \text { Biomass combustion PTLS } \\
\neg-\text { Biomass gasification PTLS } & - \text { Wind offshore PTLS } \\
\hline
\end{array}
$$

Fig. 4. Annual electricity production for the major biomass technologies and offshore wind energy in the OTLS (black symbols) and PTLS (white symbols) from 2001 to 2020 .

For onshore wind, growth in annual added capacity varies little between the OTLS and PTLS (see Figs. 3 and 5). In both cases, annual added capacity is mainly limited by the availability of low-cost geographical potential in the EU-25 countries. Total installed capacity increases to about $107 \mathrm{GW}$ in 2020 , corresponding to an annual production of about $247 \mathrm{TWh}$ in 2020 . This capacity falls well within the range of the WETO/WEO scenarios and is also similar to results of scenarios without endogenous technological change. Thus, onshore wind can be regarded as a relatively robust option, which does not greatly depend on further cost reductions.

In both the OTLS and the PTLS, offshore wind capacity increases continuously until 2020 (see also Fig. 4). From 2014 onwards, annual additions start to slow down in the optimistic learning scenario, and total diffusion in 2020 in the OTLS $(7.3 \mathrm{GW}, 22 \mathrm{TWh})$ is lower than in the PTLS $(11 \mathrm{GW}, 36 \mathrm{TWh})$, as a result of the advantageous development of other technologies, especially biomass gasification.

Biomass gasification displays by far the most differing trends in the two scenarios. In the OTLS, the annually installed capacity increases rapidly from 2014 onwards and reaches about $24 \mathrm{GW}$ in 2020 , corresponding to $133 \mathrm{TWh}$. Contrary, in the PTLS, biomass gasification capacity remains marginal until 2018, and only starts to increase in capacity in the last two years of the chosen time frame (see also Fig. 4), reaching $5 \mathrm{GW}$ by 2020 . This is clearly due to the different investment costs assumed in both scenarios. With $1600 € / \mathrm{kW}$, gasification can compete with more expensive forms of biomass combustion, leading to a rapid increase in capacity, which in turn leads to further cost reductions. In the PTLS, where investment costs are $25 \%$ higher, gasification remains a niche option for five more years. This indicates, that the outcome of the scenarios is highly sensitive to (assumptions about) technological development for biomass gasification.

Finally, Table 4 gives an overview of the reduction of investment costs in 2020, compared to 2001 in the OTLS and PTLS. The impact of different assumptions about learning is clearly visible in the resulting investment cost level. For some technologies, such as biomass gasification, the faster cost decrease leads to higher installed capacities, thereby lowering costs further. The lower investment costs in the OTLS are reflected in lower overall production costs for all technologies concerned, as further described in Section 4.4.

\subsection{Competition among renewable technologies}

The strong cost reduction of biomass gasification technology in the OTLS does have an effect on the competitiveness between a number of RES-E options. Biomass gasification will mainly compete with other biomass options for the biomass supply. This is clearly shown in Fig. 5. Biomass combustion and biomass CHP both lose significant shares compared to the PTLS. However, the ultimate competition is based on the price of electricity, and thus biomass gasification also competes with offshore wind energy. As biomass gasification strongly determines the outcome of the OTLS, another scenario was evaluated: OTLS-LG (late gasification). In this scenario the rate of technological learning and cost reductions for wind onshore, wind offshore and PV are the 

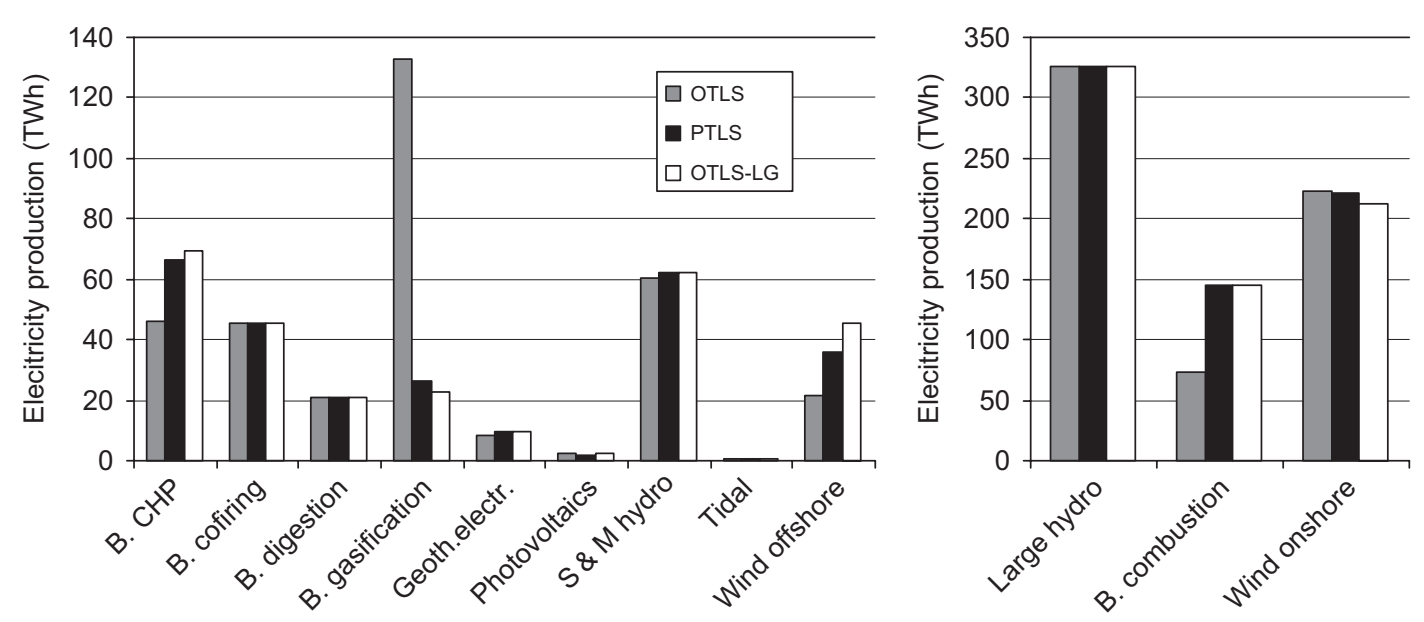

Fig. 5. Overview of electricity production levels in the OTLS and PTLS. The OTLS-LG scenario analyses the case with optimistic learning assumptions for offshore wind but pessimistic assumptions for biomass gasification.

Table 4

Investment costs level in 2020, and relative cost reduction compared to 2001 in the different technological learning scenarios

\begin{tabular}{lll}
\hline & OTLS $€ / \mathrm{kW}(\%$ of 2001$)$ & PTLS $€ / \mathrm{kW}(\%$ of 2001$)$ \\
\hline PV & $1840(34 \%)$ & $2160(40 \%)$ \\
Wind onshore & $390-560(45 \%)$ & $460-660(53 \%)$ \\
Wind offshore & $1100-1350(65 \%)$ & $1230-1520(73 \%)$ \\
Biomass gasification & $1120(33 \%)$ & $1770(52 \%)$ \\
\hline
\end{tabular}

same as in the OTLS, but for biomass gasification, the pessimistic assumption for biomass gasification are used. The aim was mainly to analyse whether offshore wind would gain substantially more market share against the biomass combustion options. The results show, that this is only partially the case: RES-E production is $25 \%$ higher than in the PTLS, but this is still substantially less than the RES-E production from biomass gasification in the OTLS. The outcome of this exercise is also depicted in Fig. 5.

\subsection{Options for individual countries}

Depending on the potentials for specific technologies, individual MS have different possibilities for achieving their RES-E targets. The different technological learning scenarios have an impact on the costs of these technologies relative to each other and therefore may impact the costs and structure of the preferred technology mix of a Member State.

Roughly two different patterns are observed. On the one hand, a number of countries have significant wind offshore potentials but limited cheap domestic biomass resources (such as Denmark and the UK). For these countries, the model results indicate that in the OTLS and PTLS similar amounts of offshore wind capacity is installed. On the other hand, in countries in Central and Eastern Europe, where biomass is one of the major renewables resources, the main competition is among biomass combustion, biomass CHP and biomass gasification, depending on the technology-learning scenario. Finally, some countries do not greatly rely on either of these options, and do not show large differences in technology choices. Nevertheless, these countries are also facing higher costs if technology learning progresses at a lower pace, as in the PTLS. For a more elaborate comparison of the effects in individual countries, see Junginger (2005).

\subsection{The costs of achieving the targets and learning investments}

The costs of achieving the $24 \%$ target differ due to different technology costs and differences in technology choices. In Table 5, the costs in both scenarios in 2020 are compared.

The additional production costs represent the costs of the options additional to the electricity commodity price, assuming no separate investment support is given (see Section 2.1.3). The $24 \%$ difference between total additional production costs in the OTLS and PTLS reflects the fact that in the PTLS, the production mix of RES-E consists of more expensive technologies. Government expenditures represent the amount of money spent in order to stimulate renewables deployment. It is evident that the higher cost level in the PTLS, which results in a one-cent higher equilibrium price, causes expenditures in 2020 to be significantly higher with $43 \%$.

The difference between total expenditures and additional production costs is the producers' surplus. In the PTLS, the 
Table 5

Overview of costs for the EU-25 in 2020

\begin{tabular}{llllll}
\hline & $\begin{array}{l}\text { Total additional } \\
\text { production costs } \\
\text { (bln euro) }\end{array}$ & $\begin{array}{l}\text { Total expenditures } \\
(\text { bln euro })\end{array}$ & $\begin{array}{l}\text { Equilibrium price }^{\mathrm{a}, \mathrm{b}} \\
(€ \mathrm{ct} / \mathrm{kWh})\end{array}$ & $\begin{array}{l}\text { Green market size }^{\mathrm{c}} \\
(\mathrm{TWh})\end{array}$ & $\begin{array}{l}\text { Average additional cost }^{\mathrm{b}, \mathrm{d}} \\
(€ \mathrm{ct} / \mathrm{kWh})\end{array}$ \\
\hline OTLS & 9.0 & 14.2 & 2.1 & 661 & 1.4 \\
PTLS & 11.1 & 20.3 & 3.1 & 648 & 1.7 \\
\hline
\end{tabular}

${ }^{\mathrm{a}}$ For definition, see Section 2.1.3.

${ }^{\mathrm{b}}$ On top of a electricity commodity price of $5 € \mathrm{ct} / \mathrm{kWh}$.

${ }^{c}$ Note that roughly one-third of the total RES-E production does not participate in the TREC market and does not receive any additional financial support. This 'grey' part of the market consists mainly of large hydropower and waste-to-energy production. Production costs of the 'grey market' are covered by the electricity commodity price and therefore not included. All technologies with productions costs lower than the commodity price (mainly hydropower) are not included.

${ }^{\mathrm{d}}$ The average additional cost level of all RES-E technologies, of which TRECs are traded in 2020.

producers' surplus is much larger than in the OTLS, indicating that the cost level of the majority of the supply options in the PTLS is comparable to the OTLS, but that the costs of the marginal option (which determine the equilibrium price) appear to be substantially higher. Indeed, the marginal option in the PTLS appears to be biomass gasification, which is needed for achieving the targets, but assumed to be still relatively expensive in 2020 in this scenario. This shows that in a market-based system, where total expenditures are determined by the price of the marginal option, the quota and penalty level should be determined with great care, because a high equilibrium price can cause large windfall profits for the majority of RES-E producers.

From Fig. 6 some additional insights in the development of production costs over time can be gained. Obviously, the total cost increase corresponds to an increase in production levels. The difference in investment cost levels between OTLS and PTLS increases over time, causing the diverging trend of the production costs levels. In the period after 2012, the competition between technologies is enhanced, leading to stronger cost reductions for the 'winners' in the market. Furthermore, there is a significant cost increase visible in 2008 in both scenarios. This is due to the transition from the national support schemes to the generic policy based on the EU targets. For MS with previously low ambitions (i.e. minimal policy support instruments), this implicitly leads to an increase in ambition level and therefore a peak in the costs. Indeed, transitions from one support scheme to another always encompass some risks and a change in ambition level should be implemented in a gradual fashion.

The overall goal of all RES-E support-be it RD\&D or operational support - is to establish a cost reduction for these technologies that allows them to approach the breakeven point where they can compete with fossil based electricity generation. The sooner this is reached, the better, because it saves the expenditures related to additional support. This is particularly important given the increasing difference between the costs in OTLS compared to PTLS. Therefore, the main question would be how much RD\&D efforts are required to achieve the PRs assumed in the

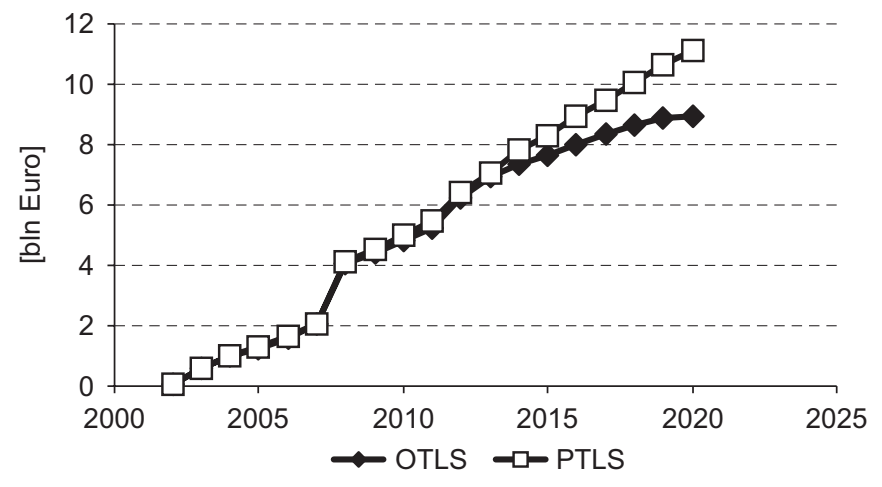

Fig. 6. Additional production costs in the two technology learning scenarios.

OTLS instead of those in the PTLS. For this purpose Kouvaritakis et al. (2000) have proposed to quantify the concept of 'investing in learning (see footnote 14) further by extending the EC described in Section 2.2 with a factor reflecting cumulative R\&D expenditures. Work on parameter estimates and applications of this two-factor learning curve is in progress, see for instance Klaassen et al. (2003) and Miketa and Schrattenholzer (2004).

Within the scope of this paper, it is not possible to determine directly the amount of R\&D spending necessary to achieve the PRs in the OTLS instead of those in the PTLS. Nevertheless, given the increasing difference between total additional production costs in OTLS and PTLS (Fig. 6), there is a clear trade-off between investing in learning by searching - reflected in RD\&D expendituresand learning by doing - reflected in direct support expenditures. For technologies that are approaching the point of large scale market introduction, such as offshore wind and biomass gasification, it seems particularly worthwhile to invest in pilot plants and demonstration projects in order to reduce their costs. Risks associated with these investments are limited because experience has already been gained. For illustration, the total difference in additional production costs between 2001 and 2020 between the OTLS and PTLS is 9600 million Euro, i.e. about 480 million Euro per year on average. For comparison, in 1998, the individual EU-15 MS and the EU spent in total 
(as a rough estimate) about 400 million Euro on public RD\&D. ${ }^{19}$ In other words, given the assumptions on a harmonization policy scenario and technology development, the model illustrates that higher technological progress and associated cost reductions may result in savings for market introduction measures in the same order of magnitude as current public RD\&D expenditures. ${ }^{20}$

\section{Methodological discussion}

Regarding the methodology followed on implementing endogenous learning, a number of limitations of the present study have to be highlighted. First of all, assumptions had to be made for the capacity growth in the ROW. These are mainly influencing the development and cost of solar electricity, as already in 2001, about $88 \%$ of all PV capacity was installed outside the EU25, and this share is assumed to increase until 2020 to $93-95 \%$. Therefore, cost reductions for PV are only to a limited extent modelled endogenously. For onshore wind this share is both less high (22\% in 2001 and $46 \%$ in 2020$)$, and less relevant, as the results show that it is already a low-cost option, and does diffuse strongly in both scenarios. For offshore wind, technological change and cost reductions will to an even larger extent depend on developments within Europe. It is expected that only about $2 \mathrm{GW}$ of offshore wind capacity is placed outside the EU-25 until 2020 , compared to $7-22 \mathrm{GW}$ in Europe. Therefore, the influence of this ROW-capacity on the cost reductions is relatively small.

A similar methodological issue is the modelling of cost reductions of large-scale biomass gasification plants. The year 2014 was chosen as introduction year in the OTLS, as a 10-year time period was deemed the minimum required time span to develop such large-scale plants. However, the choice of how many pilot plants are built until 2014 (and thus how far investment costs may decline) is of course somewhat arbitrary. From 2014, biomass gasification technology is implemented extremely fast: about $24 \mathrm{GW}$ of capacity in only six years. This growth is equivalent to 40 plants (of $100 \mathrm{MW}$ each) per year. While such a growth rate may seem unrealistic at first glance, it has to be placed in a larger frame. First, the total thermal capacity in the EU-25 in 2001 was about $380 \mathrm{GW}$ (EIA, 2004). Assuming an average life span of 30 years, more than $12 \mathrm{GW}$ of thermal capacity have to be replaced each year (not even accounting for increasing electricity demand until 2014/

\footnotetext{
${ }^{19}$ This estimate is based on two main figures. First, the spending of individual MS was approximately 265 million Euro in 1998 (IEA, 2005, based on 254 million US\$ of 2002). Second, in the 5th framework programme of the EU (1998-2002), 1042 million Euro were spent on RD\&D for all energy technologies except nuclear energy (EU CORDIS, 2005). Based on the program content, it was assumed that roughly half of this amount was spent on renewables, resulting in annual expenditures of about 130 million Euros on RD\&D for renewables.

${ }^{20}$ However, an unknown (but probably substantial) amount of private RD\&D was not included in this comparison.
}

2020). Thus, capacity additions of $4 \mathrm{GW}$ per annum within the EU-25 are quite feasible. Second, the gasification capacity in the OTLS is basically replaced by other biomass combustion options (and offshore wind) in the PTLS scenario. The total biomass capacity growth is mainly limited by the available biomass supply. Third, such a rapid diffusion of a new technology as modelled in the OTLS is not common, but also not impossible. For example, the combined cycle gas turbine capacity in only 6 EU countries (UK, the Netherlands, Germany, Italy, Belgium and Finland) increased from 1.9 GW in 1990 to over $30 \mathrm{GW}$ in 1997 (Watson, 1997). Thus, it is concluded that the strong diffusion is optimistic, but certainly not unrealistic.

In addition, no assumptions were made in the OTLS on further growth of biomass gasification in the ROW after 2014. Given the low investment costs, it is plausible that also outside the EU-25, gasification capacity would drastically increase, as especially the global pulp and paper industry and the sugar industry are likely to embrace biomass gasification technology. Additional learning and cost reductions would probably occur, possibly further lowering electricity production costs. Thus, overall costs to reach the target of $24 \%$ RES-E in 2020 may be even lower than modelled. On the other hand, this does have little influence on the OTLS scenario outcome in terms of capacity and electricity production volumes, as these are already limited by the available biomass supply.

Furthermore, it should be mentioned that the results of the analysis to some extent depend on the assumed size of the quota, which determines the demand for RES-E in Europe. The ambition level of this quota and the underlying policy target is expected to affect particularly wind offshore and biomass gasification, the technologies that already proved to be most sensitive to the different scenarios analyzed in this paper. Changes in projected electricity demand, for instance due to learning effects and efficiency improvements on the demand side, or due to higher oil prices, are proportionally translated into changes in RES-E demand.

The biomass supply is another issue deserving explicit attention. Especially for the NMS, so far, relatively modest assumptions on the availability of biomass (such as energy crops and forest residues) have been made in ADMIRE REBUS. Recent results from the EU-funded Viewls study (van Dam and Faaij, 2004) show that especially the potential from energy crops such as willow may be over a factor of 10 higher than assumed so far or countries like Poland, also at relatively low costs. This would have a profound influence on the competitiveness of all biomass options. Also, no trade of biomass between MS was modelled. If this would have been implemented, the TREC import/ export balances of individual MS may have developed differently. Furthermore, so far, import of biomass from outside the EU-25 was not included in the model, which may lead to an underestimate for RES-E production from biomass. A larger diffusion of biomass 
technologies may in turn also have resulted in higher learning effects. On the other hand, increased demand for biomass for biofuel production may again limit the available biomass potential for RES-E production. All these issues should be further investigated.

The recent increases in world oil prices, up to $\$ 50-70$ per barrel in 2005 will only to a limited extent affect the results presented in this article. The oil price increase is reflected in higher electricity prices, mainly through the linkage between gas and oil prices that exists in many European countries. This impact is stronger in those countries where natural gas dominates the power generation mix, as in the Netherlands, but it will hardly affect competition among the RES-E technologies within a MS. It will cause some shifts in the competitiveness of RES-E technologies in different EU Member States. Generally, higher electricity prices lead to a lower cost gap for RES-E technologies, and better chances for renewable electricity options to compete with regular power generation. Similarly, the position of biofuels in the transportation sector improves with high oil prices, which in turn might affect the amount and price of biomass available for electricity generation. Although these impacts are beyond the scope of this article, they deserve a further investigation.

Another issue are additional costs caused by high penetration levels of intermittent electricity sources. In the ADMIRE REBUS model, no modelling is performed concerning physical consequences on the power system. With high penetration degrees of intermittent electricity sources, additional investments are required (due to the increased need for back-up capacity and/or electricity storage, spinning reserve, and potentially an increasing amount of discarded electricity). To compensate for these costs, an intermittency penalty of $0.5 € \mathrm{ct} / \mathrm{kWh}$ is currently used in ADMIRE REBUS. The actual share of intermittent energy sources (onshore wind, offshore wind and $\mathrm{PV}$ ) in 2020 is about $7 \%$ of the predicted demand of $4 \mathrm{PWh}$ in the EU-25 in both OTLS and PTLS scenarios. According to a recent study for European OECD countries, at $7 \%$ penetration level, overall additional costs are likely far lower than $0.5 € \mathrm{ct} / \mathrm{kWh}$ (Hoogwijk, 2004). However, as large amounts of (especially offshore wind) power may be fed into the grid at a single connection point, the costs of grid fortification may be locally high for areas like northern Germany, Denmark, the Netherlands and the UK.

Finally, it should be noted that the penetration of renewable technologies depends not only on costs and learning effects, but also on policy instruments used by governments to stimulate these technologies. In the current analysis, the choice was deliberately made to design a neutral but plausible policy scenario, in which different technologies compete in a market-based system. Although this provides a solid background for comparing the effects of different technology learning scenarios, it is not a forecast. For comparison, a less ambitious policy scenario, involving a continuation of present, technology specific, policies and no international trade, was also examined, see Junginger (2005).

\section{Conclusions}

This article has presented results of a model simulation, focusing on prospects for RES-E technologies under different technological learning scenarios. The results provide a basis for further understanding the role of technological learning for technologies that are close to market penetration. The analysis has assumed a moderately ambitious policy scenario, where technologies have to compete in a market situation in the period beyond 2012 . In practice, regardless of the policy instruments chosen, competition between the different technologies available for RES-E generation will certainly play an important role. Competition will not only involve economic aspects, but also potentials for renewables deployment, as taken into account in the model evaluation.

Against this background, consequences of technological development on the market success of technologies may be largest for offshore wind and biomass gasification. For biomass gasification, the direct impact of optimistic technological learning assumptions can be strong. However, the large difference between the OTLS and PTLS indicates a large uncertainty on future prospects for this technology. On the other hand, for offshore wind, the realised cost reduction in the OTLS does not lead to a higher penetration than in the PTLS, due to the stronger position of biomass gasification on the European market. It illustrates the importance of viewing individual technology diffusion trends in a system approach.

More robust trends are observed for onshore wind and photovoltaic electricity production. Diffusion of wind onshore does not greatly depend on further cost reductions, but rather on the remaining potential available on attractive sites. For PV, the lower PR in the OTLS allows the technology to become competitive in Mediterranean countries. However, the impact of endogenous learning is limited because over $90 \%$ of all PV capacity is installed outside the EU-25.

For individual countries, technology diffusion trends may be different from the overall picture, due to their domestic resource base, and the possibility to trade their production in view of achieving the European targets for RES-E. For some countries, there is a choice between wind offshore and biomass gasification, depending on their costs, while other countries shift between different biomass technologies. Trade flows also differ between scenarios, due to different geographical distribution of the wind and biomass potentials. Still, in the PTLS, all countries are facing higher costs for achieving their RES-E targets.

Given the finding that the diffusion trends for offshore wind and biomass gasification are most sensitive to learning effects (under a harmonization policy scenario), learning investments are particularly expected to pay off for these technologies. These technologies seem to be on 
the edge of competitiveness with more established RES-E options such as onshore wind and biomass combustion, and have significant potentials for contributing to an increased share of RES-E in the European Union. Moreover, investment in pilot plants or demonstration projects for technologies that are already close to the market has high success rates.

In a market-based system, total expenditures are to a great extent determined by the price of the marginal option. Therefore, in order to avoid large windfall profits for RES-E producers, the ambition level of the target and the height of the penalty level are important design variables. Alternative ways to keep the equilibrium price on the TREC market within acceptable ranges include the provision of investment support for more expensive options, or, in a sufficiently large market, introduction of separate quota for groups of technologies depending on their level of maturity.

\section{Acknowledgements}

This research was carried out within the framework of the 'Stimuleringsprogramma Energieonderzoek', which was set up by the Netherlands Organization for Scientific Research (NWO) and Novem (Nederlandse Onderneming voor Energie en Milieu). The financial support from NWO/ Novem is gratefully acknowledged.

\section{References}

Anonymous, 2004. Slovakia backs away from renewables target, ENDS (Environmental daily), 1703, July 12, 2004, available at <www. environmentdaily.com $>$.

Argote, L., Epple, D., 1990. Learning curves in manufacturing. Science 247, 920-924.

BCG, 1968. Perspectives on Experience. Boston Consulting Group Inc.

BTM, 2000. International Wind Energy Development. World market update 1999. Ringkøbing, Denmark, BTM Consult ApS, p. 71.

Claeson Colpier, U., Cornland, D., 2002. The economics of the combined cycle gas turbine. An experience curve analysis. Energy Policy 30 (4), 309-316.

Daniëls, B.W., Uyterlinde, M.A., 2005. ADMIRE-REBUS: modeling the European market for renewable electricity. Energy 30 (14).

de Noord, M., Beurskens, L.W.M., de Vries, H.J., 2004. Potentials and costs for renewable electricity generation. A data overview. ECN-C03-082. Petten, The Netherlands, Energy Research Centre of the Netherlands.

de Vries, H., 2004. Assumptions for ADMIRE-REBUS on the 10 new member countries. Petten, the Netherlands, Energy research Centre of the Netherlands. Draft report.

de Vries, H.J., Roos, C.J., Beurskens, L.W.M., Kooijman-van Dijk, A.L., Uyterlinde, M.A., 2003. Renewable electricity policies in EuropeCountry fact sheets 2003. ECN-C-03-071. Petten, The Netherlands, Energy Research Centre of the Netherlands.

EIA, 2004. International Electricity Information Page. Washington, DC, USA, Energy Information Administration 〈http://www.eia.doe.gov/ emeu/international/electric.html\#IntlCapacity $\rangle$, accessed in October 2004.

EREF, 2004. Missing Targets-How European Countries are failing to Achieve its Renewable Electricity Targets, Update 2004. available at $\langle$ http://www.eref-europe.org/docs/documents.htm 〉, European Renewable Energies Federation.
EU CORDIS, 2005. Description of the 5th framework, Energy, Environment and Sustainable Development projects, Part B: Energy, key targets $5 \& 6$. EU community research \& development information service (CORDIS) website, available at 〈www.cordis.lu/eesd/src/ proj_eng.htm $>$.

European Commission, 2003. World energy, technology and climate policy outlook WETO-2030. Office for Official Publications of the European Communities, European Commission, Directorate-General for Research Energy, Luxembourg.

European Commission, 2004. The share of renewable energy in the EU. Communication from the Commission to the Council and the European Parliament, COM(2004)366 final, 26 May, 2004.

Faaij, A., Meulemann, B., van Ree, R., 1998. Long term Perspectives of Biomass Integrated Gasification/Combined Cycle (BIG/CC) technology. Costs and Efficiency and a comparison with Combustion. Utrecht, The Netherlands, Department of Science, Technology and Society, Utrecht University.

Gerlagh, R., van der Zwaan, B.C.C., 2004. A Sensitivity Analysis of Timing and Costs of Greenhouse Gas Emission Reductions. Climatic Change 65 (1), 39-71.

Goldemberg, J., Johansson, T.B., 2004. World Energy Assessment. Overview 2004 update. New York, USA, United Nations Development Programme, p. 85.

Hoogwijk, M.M., 2004. On the global and regional potential of renewable energy sources. Doctoral Thesis, Utrecht University, p. 256.

Huber, C., 2004. The toolbox Green-X. Vienna, Austria, Vienna University of Technology, Energy Economics Group.

IEA, 2005. IEA Energy statistics-R\&D database. available at <http:// library.iea.org/dbtw-wpd/Textbase/stats/rd.asp $\rangle$, International Energy Agency.

IEA/OECD, 2002. World Energy Outlook 2002. Paris, France, International Energy Agency/Organisation for Economic Cooperation and Development.

IEA/OECD, 2003. Renewables for power generation: Status \& Prospects. Paris, France, International Energy Agency/Organisation for Economic Cooperation and Development.

Jansen, J.C., Uyterlinde, M.A., 2004. A fragmented market on the way to harmonization? EU policy-making on renewable energy promotion. Energy for Sustainable Development 8 (1), 93-107.

Junginger, M., 2005. Learning in renewable energy technology development. Doctoral Thesis, Promotor W.C. Turkenburg, Co-promotor A.P.C. Faaij, Utrecht University, May 2006, p. 216.

Junginger, M., Faaij, A., Turkenburg, W., 2004a. Global experience curves for wind farms. Energy Policy 33 (2), 133-150.

Junginger, M., Faaij, A., Turkenburg, W.C., 2004b. Cost reduction opportunities for offshore wind farms. Wind Engineering 28 (1), 97.

Klaassen, G., Miketa, A., Larsen, K., Sundqvist, T., 2003. The impact of R\&D on innovation for wind energy in Denmark, Germany and the United Kingdom. Laxenburg Austria, International Institute for Applied Systems Analysis.

Koornneef, J., 2004. Technological learning in fluidized bed combustionan experience curve approach. Utrecht, The Netherlands, Copernicus Institute, Utrecht University, p. 80.

Kouvaritakis, N., Soria, A., Isoard, S., 2000. Modelling energy technology dynamics: methodology for adaptive expectations models with learning by doing and learning by searching. International Journal of Global Energy Issues 14 (1-4), 104-115.

Laitner, J.A., 'Skip' and Sanstad, A.H., 2004. Learning-by-doing on both the demand and the supply sides: implications for electric utility investments in a Heuristic model. International Journal of Energy Technology and Policy 2 (1/2), 142-152.

Linden, N.H.v.d., Jansen, J.C., Uyterlinde, M.A., Bürger, V., Garcia, F.R., Green, J., Timpe, C., Vrolijk, C., White, S., Yerro, G.P., 2004. Guarantees of origin as a tool for renewable energy policy formulation. ECN C-04-078, Petten, The Netherlands, Energy Research Centre of the Netherlands.

Mantzos, L., Capros, P., Kouvaritakis, N., Zeka-Paschou, M., 2003. European Energy and Transport Trends to 2030. Available at $<\mathrm{http}: / /$ 
europa.eu.int/comm/dgs/energy_transport/figures/trends_2030/index_ en.htm $>$, European Communities.

McDonald, A., Schrattenholzer, L., 2001. Learning rates for energy technologies. Energy Policy 29 (4), 255-261.

Miketa, A., Schrattenholzer, L., 2004. Experiments with a methodology to model the role of R\&D expenditures in energy technology learning processes; first results. Energy Policy 32, 1679-1692.

Molly, J.P., Ender, C., 2004. Wind energy study 2004. Assessment of the wind energy market until 2012. Presented at the WindEnergy International Trade Fair, Hamburg, 11-14 May 2004, Hamburg Messe und Congress $\mathrm{GmbH}$.

Morthorst, P.E., 2000. The development of a green certificate market. Energy Policy 28 (15), 1085-1094.

Neij, L., Dannemand Andersen, P., Durstewitz, M., Helby, P., HoppeKilpper, M., Morthorst, P.E., 2003. Experience Curves: A tool for energy policy assessment (EXTOOL).

Nordhaus, W.D., 1993. Rolling the 'DICE': an optimal transition path for controlling greenhouse gases. Resource and Energy Economics 15 (1), 27-50.

Peck, S.C., Teisberg, T.J., 1992. CETA: a model for carbon emission trajectory assessment. The Energy Journal 13 (1), 55-77.

Reiche, D., Bechberger, M., Körner, S., Laumanns, U., 2003. Handbook of Renewable Energies in the European Union II. Case studies of all Accession States. Frankfurt, Germany, Peter Lang $\mathrm{GmbH}$.

Schaeffer, G.J., Alsema, E., Seebregts, A., Beurskens, L., Moor, H.d., Durstewitz, M., Perrin, M., Boulanger, P., Laukamp, H., Zuccaro, C., 2004. Learning from the Sun. Analysis of the use of experience curves for energy policy purposes: the case of photovoltaic power. Final report of the Photex project. ECN-C-04-035. Petten, The Netherlands, Energy research Centre of the Netherlands.

Seebregts, A.J., Kram, T., Schaeffer, G.J., Stoffer, A., Kypreos, S., Barreto, L., Messner, S., Schrattenholzer, L., 1999. Endogenous technological change in energy system models, Synthesis of Experience with ERIS, MARKAL and MESSAGE. ECN-C-99-025. Petten, The Netherlands, Energy Research Centre of the Netherlands.

Uyterlinde, M.A., Daniels, B.W., de Noord, M., Vries, H.d., ZoetenDartenset, C.d., Skytte, K., Meibom, P., Lescot, D., Hoffmann, T., Stronzik, M., Gual, M., Rio, P.d., Hernandez, F., 2003. Renewable electricity market developments in the European Union: final report of the ADMIRE REBUS project. ECN-C-03-082. Petten, The Netherlands, Energy research Centre of the Netherlands.

van Dam, J., Faaij, A., 2004. Viewls. Biomass potential and costs in CEEC, WP3. Draft Report. van der Zwaan, B.C.C., Seebregts, A., 2004. Endogenous learning in climate-energy-economic models - an inventory of key uncertainties. International Journal of Energy Technology and Policy $2(1 / 2)$, $130-141$.

van der Zwaan, B.C.C., Gerlagh, R., Klaassen, G., Schrattenholzer, L., 2002. Endogenous technological change in climate change modelling. Energy Economics 24, 1-19.

Verbruggen, A., 2004. Tradable green certificates in Flanders (Belgium). Energy Policy 32 (2), 165-176.

Voogt, M.H., Uyterlinde, M.A., de Noord, M., Skytte, K., Nielsen, L.H., Leonardi, M., Whiteley, M., Chapman, M., 2001. Renewable energy burden sharing-REBUS - Effects of burden sharing and certificate trade on the renewable electricity market in Europe, ECN-C-01-030, Petten, The Netherlands.

Watson, W.J., 1997. Constructing success in the electric power industry: combined cycle gas turbines and fluidized beds. Doctoral Thesis, University of Sussex, p. 439.

Westwood, J., 2004. Global energy trends. Presentation available at $\langle$ http://www.dw-1.com 〉, Douglas-Westwood Limited.

Whiteley, M., Zervos, A., Timmer, M., Butera, F., 2003. Final Report of the MITRE Project. Overmoor, UK, ESD.

\section{Glossary}

ADMIRE REBUS: Assessment and dissemination on major investment opportunities for renewable electricity in Europe using the REBUS tool.

$B I G / C C$ : Biomass integrated gasification/combined cycle.

CoE: Cost of electricity.

$E C$ : Experience curve.

$E U$-25: The European Union as of May 1st 2004, including 25 member states.

OTLS: Optimistic technological learning scenario.

PTLS: Pessimistic technological learning scenario.

$P R$ : Progress ratio.

ROW: Rest of the world (all countries outside the EU-25).

WEO: World Energy Outlook 2002 (IEA/OECD, 2002).

WETO: World Energy, Technology and climate policy Outlook (European Commission, 2003).

$R E S-E$ : Electricity from renewable energy sources.

$R G P$ : Required green price.

$M S$ : Member states of the EU.

NMS: The 10 new member states of the EU.

TRECs: Tradable Renewable Energy Certificates. 